\title{
The Effects of Ficus Carica Fruit on Bone Markers and Oestrogen Level of Post-Menopausal Osteoporotic Rats
}

Norfarah Izzaty R, Nur Adlina M, Mohd Dzulkhairi MR, Muhammad Shamsir MA, Nadia ME*

Faculty of Medicine and Health Sciences, Universiti Sains Islam Malaysia, Menara B, Persiaran MPAJ, Jalan Pandan Utama, Pandan Indah, 55100 Kuala Lumpur, Malaysia.

\section{ABSTRACT}

Introduction: Post-menopausal osteoporosis is the most common type of osteoporosis, which occurs due to a deficiency of oestrogen following menopause. Considering the adverse effects of oestrogen replacement therapy, natural products may serve to replace the current conventional treatment. Ficus carica $(\mathrm{FC})$ which is commonly known as fig may have a potential in treating post-menopausal osteoporosis due to their abundance of important minerals and bioactive compounds such as phenolic, flavonoid and anthocyanins. This study aimed to evaluate the effects of FC on bone metabolism of ovariectomized rats. Materials and Methods: Fifty-six female Spraque-Dawley rats were randomly divided into seven groups; SHAM operated (SHAM), ovariectomized control (OVX), ovariectomized $+64.5 \mu \mathrm{g} / \mathrm{kg}$ oestrogen (ERT), ovariectomized +50 $\mathrm{mg} / \mathrm{kg}$ aqueous extract of FC (AQ50), ovariectomized $+100 \mathrm{mg} / \mathrm{kg}$ aqueous extract of $\mathrm{FC}$ (AQ100), ovariectomized $+50 \mathrm{mg} / \mathrm{kg}$ raw FC (RW50), and ovariectomized $+100 \mathrm{mg} / \mathrm{kg}$ raw FC (RW100). After eight weeks of treatments, rats were euthanized and femurs were dissected out to measure bone osteocalcin, Ctelopeptide of type 1 collagen and bone estrogen level. Results: RW50 and RW100 showed an increasing trend in osteocalcin levels and also oestrogen level, but no significant difference between all groups. RW50 and RW100 also showed significantly reduced C-telopeptide of type 1 collagen levels compared to OVX group. Conclusion: These findings suggested that raw FC at the doses of $50 \mathrm{mg} / \mathrm{kg}$ and $100 \mathrm{mg} / \mathrm{kg}$ have potential to improve bone in treating post-menopausal osteoporosis. However, this need to be confirmed with higher doses.

KEYWORDS: post-menopausal osteoporosis; Ficus carica; bone marker; osteocalcin; CTX-1

\section{INTRODUCTION}

Osteoporosis is an asymptomatic skeletal disease with decreased bone mineral density and bone mass as well as micro-architectural deterioration of bone. ${ }^{1}$ This disease also has been widely known as one of the main public health problems associated with ageing especially among post-menopausal women. Post-menopausal osteoporosis (PMO) is the primary cause of osteoporosis due to reduction of ovarian oestrogen level after menopause which

Corresponding Author

Dr. Nadia Mohd Effendy

Faculty of Medicine and Health Sciences, Universiti Sains Islam Malaysia, Menara B, Persiaran MPAJ, Jalan Pandan Utama,

Pandan Indah, 55100 Kuala Lumpur, Malaysia.

Tel: $+603-42891162$

Email: nadia@usim.edu.my effects the bone to lose its strength and prone to fracture especially at wrist, hip and spine. $^{2}$ Oestrogen plays a crucial part in maintaining bone structure and density ${ }^{3}$ through various mechanisms involving bone cells such as osteoblasts, osteocytes and osteoclasts and immune cells which function at balancing the bone resorption and bone formation. ${ }^{4}$ Therefore, deficient in oestrogen level may cause bone resorption to outweigh the bone formation and induce bone loss predominantly trabecular bone, about $3 \%$ to $5 \%$ within 5 to 10 years. ${ }^{2}$ In osteoporosis, trabecular bone is more prone to be affected. This is because the trabecular bone is metabolically more active and regularly remodelled than cortical bone. ${ }^{5,6}$ Hence, the loss of bone can be observed with an increment of trabecular separation and decline in trabecular bone volume fraction as well as bone trabecular number. ${ }^{6}$ 
Estrogen replacement therapy (ERT) is the main medication in treating and preventing bone loss in postmenopausal osteoporosis. However, the adverse effects associated with the long-term use of ERT have been revealed which include breast cancer, uterine cancer and stroke. These adverse effects are reported to outweigh its benefits. ${ }^{7}$ Hence, the intake of ERT has been revised and restricted due to safety concerns. $^{8}$ Besides, there are other pharmacological treatments available, approved by Food and Drug Administration (FDA) such as bisphosphonate, calcitonin, selective estrogen receptors modulators (SERM) including raloxifene, arzoxifene and lasofoxifene which may help in increasing the bone mass and preventing bone loss and fracture. However, these drugs also possess side effects such as renal problem, eye inflammation, osteonecrosis of the jaw bone, malignancy and increased risk of deep vein thrombosis. ${ }^{9,10}$ This has led to the discovery of alternative anti-osteoporotic agents based on natural products with minimal side effects.

Natural products such as turmeric, Nigella sativa (black seed), Labisia pumila (kacip fatimah) and Piper sarmentosum (daun kaduk) are widely used traditionally by women as these plants possess many therapeutic benefits. ${ }^{11-14}$ These plants contain abundance of anti-oxidative compounds. It has been shown that, antioxidant compounds can improve bone quality by inducing endogenous anti-oxidative enzymes such as superoxide dismutase, catalase and glutathione peroxidase. ${ }^{15}$ These anti-oxidative enzymes will help in scavenging oxidative stress, which is known to contribute to bone loss. Another widely cultivated plant nowadays is Ficus carica (FC) or also known by the locals as figs or 'buah tin'. Figs are widely cultivated worldwide such as in Turkey, Egypt, Spain and Asian countries such as Malaysia. ${ }^{16}$ However, there is paucity in literature on the therapeutic benefits of figs. This plant is rich in minerals which is responsible in promoting bone health such as strontium, magnesium, phosphorus, iron and calcium. ${ }^{17} \mathrm{FC}$ contains a lot of bioactive compounds such as phenolic (10.90 $\mu \mathrm{g} \mathrm{GAE} / \mathrm{mg}$ sample), flavonoid (2.7 $\mu \mathrm{g} \mathrm{CE} / \mathrm{mg}$ sample), alkaloid $(9.6 \%)$, saponin $(0.59 \%)$ and anthocyanin $(100 \mathrm{mg} /$ 100 g). ${ }^{17,18}$ Quercetin rutinoside was the main individual phenolic compound found in fig which is $16 \mathrm{mg} / 100 \mathrm{~g}$ of fresh weight for peel while 1.8 $\mathrm{mg} / 100 \mathrm{~g}$ of fresh weight for pulp. Meanwhile, the main anthocyanin present in fig was cyanidin-3- rutinoside; $108.9 \mathrm{mg} / 100 \mathrm{~g}$ for peel and $9.5 \mathrm{mg} / 100$ $\mathrm{g}$ for pulp. ${ }^{18}$

In another study done by Dudaric et al. ${ }^{19}$ they reported that these bioactive compounds were found to exert bone protective effects in maintaining bone health through anti-inflammatory, anti-oxidative and osteoimmunological effects. Studies have found that FC exerts an antiinflammatory activities as it was reported to suppress the expression of interleukin (IL) $1 B$ (IL1B), IL-6 and tumour necrosis factor alpha (TNF-a) together with inhibition of xanthine oxidase (XO) enzyme, prostaglandin ( $\mathrm{PGE}_{2}$ ), nitric oxide (NO) and lipoxygenase enzyme. ${ }^{20-24}$ Pro-inflammatory cytokines had been suggested to be involved in development of post-menopausal osteoporosis. A study by Yokota et al. ${ }^{25}$ revealed that both TNF-a and IL-6 may produce synergistic effect in inducing osteoclast differentiation. In addition, IL-1 has been found to enhance receptor activator of nuclear factor kappa-B ligand (RANKL) -induced osteoclast and stimulate osteoclast differentiation. ${ }^{26}$

Bone remodelling undergoes continuously throughout the lifetime in order to repair microcracked of bone, adapt in the changes of mechanical forces, shape the bone during bone growth and regulate bone mineral homeostasis. It can be assessed by measuring bone biochemical markers either bone formation markers including alkaline phosphatase (ALP), osteocalcin (OC), procollagen type 1 amino terminal propeptide (P1NP) or bone resorption markers which are osteoprotegerin (OPG), C-telopeptide of type 1 collagen (CTX-1), amino-Terminal cross linked telopeptides of type 1 collagen (NTX) and sclerostin. ${ }^{27}$ In the present study, we measured bone osteocalcin and CTX-1 since both markers are the most commonly used bone markers in assessing bone turnover.

Phytoestrogenic properties of plant may be beneficial in protecting post-menopausal bone loss as they have an affinity to estrogen receptor due to their structural similarity to 17-beta-estradiol which resulting in bone formation and suppression of osteoclast differentiation. ${ }^{28}$ Its effectiveness against post-menopausal bone loss has been evaluated and the results reported that they increased bone mineral density (BMD), reduce bone resorption marker, induced osteoprotegerin (OPG) and bone 
morphogenetic protein-2 (BMP-2) gene expression while down-regulating the receptor activator of nuclear kappa-B ligand (RANKL) gene expression of ovariectomized rats. ${ }^{29}$ Hence, the objectives of this study are to investigate the effects of Ficus carica on the bone markers together with estrogen level of ovariectomized rats as post-menopausal osteoporotic rat model. Bone biochemical markers were measured as it reflects specific physiological mechanisms in the bone and indicates the activity of bone metabolism as well as bone remodelling. To the best of our knowledge, this is the first study to look at the effects of Ficus carica fruit on bone metabolism and oestrogen level of post-menopausal osteoporotic rats.

\section{MATERIALS AND METHODS}

\section{Experimental Animals and Treatments}

Fifty-six female Sprague Dawley rats, aged between 5-6 months and weighing between 230 to 280 grams were supplied from the Animal Resources Unit, Universiti Putra Malaysia (UPM). They were kept in cages at a temperature of $22^{\circ} \mathrm{C}$, with 12 -hour lightdark cycle. They were fed free access to normal diet pellet (Gold Coin, Malaysia) and deionized water.

After acclimatization for a week, they were allocated into seven groups each of eight rats; Sham -operated control (SHAM), ovariectomized control (OVX), ovariectomized treated with estrogen Premarin at $64.5 \mu \mathrm{g} / \mathrm{kg}$ (ERT), ovariectomized supplemented with aqueous extract of Ficus carica at $50 \mathrm{mg} / \mathrm{kg}$ (AQ50), ovariectomized supplemented with aqueous extract of Ficus carica at $100 \mathrm{mg} / \mathrm{kg}$ (AQ100), ovariectomized supplemented with raw Ficus carica at $50 \mathrm{mg} / \mathrm{kg}$ (RW50) and ovariectomized supplemented with raw Ficus carica at $100 \mathrm{mg} / \mathrm{kg}$ (RW100).

All the treatments were given after two weeks of ovariectomy in order to ensure complete wound healing and successful bone loss induction. Approval was obtained from Animal Ethics Committee of Universiti Sains Islam Malaysia (USIM/AEC/ AUP/2016/(4)).

\section{Ovariectomy procedure}

The rats were undergone ovariectomy under anaesthesia by injecting $250 \mathrm{mg} / \mathrm{kg}$ of
Tribromoethanol. Each rat in the OVX group underwent a single two centimetres $(\mathrm{cm})$ midline ventral incision, while each rat in the control group underwent a sham procedure according to the method described by Sophocleous and Idris. ${ }^{30}$ The sham-operated rats underwent surgery where the ovaries were identified but they were left intact.

\section{Preparation of Ficus Carica and Estrogen}

The fresh and ripped $F$. carica fruits were purchased from Fig Fertigation (Kajang, Malaysia). The aqueous extract of $F$. carica was prepared by Phytes Biotek Sdn. Bhd. (Shah Alam, Malaysia). Meanwhile, raw F. carica was prepared by mixing fresh figs with deionized water to form raw fig puree. The extract and fresh figs were dissolved with deionized water and given at the dose $50 \mathrm{mg} / \mathrm{kg}$ and $100 \mathrm{mg} / \mathrm{kg}$. Estrogen Premarin ${ }^{\circledR}$ solution (Wyeth-Ayerst, Canada) was prepared by crushing the tablet containing conjugated oestrogen with mortar and pestle, diluting in deionised water and given at the dose of $64.5 \mu \mathrm{g} / \mathrm{kg}$ rat weights. All the treatments were administered daily at 9 am via oral gavage for eight weeks.

\section{Preparation of Bone Samples}

After completion of treatment, all rats were euthanized using high dose of diethyl ether. Bones were dissected out and cleaned from adhering muscle. Then, the bone samples were stored at $80^{\circ} \mathrm{C}$ until the analysis.

\section{Bone Biochemical Marker Analysis}

\section{a) Bone osteocalcin (OC)}

Bone formation marker, osteocalcin (OC) was measured using Enzyme-linked immunosorbent assay (ELISA). The kit used was Rat osteocalcin kit (Sunlong Biotech, China). Before starting the assay, the bone was rinsed with phosphate buffered saline (PBS) to remove the blood clot. Then, the bone homogenate was prepared by homogenizing $20 \mathrm{mg}$ of bone with PBS buffer, and centrifuged at $10,000 \times \mathrm{g}$ for 5 minutes. The supernatant was then collected for analysis. The concentration of osteocalcin level was measured spectrophotometrically at $450 \mathrm{~nm}$ and the assay was conducted according to manufacturer's instruction. 
b) Bone C-telopeptide of type 1 collagen (CTX-1)

Bone resorption marker, C-telopeptide of type 1 collagen (CTX-1) was analyzed by using Enzymelinked immunosorbent assay (ELISA). The kit used was Rat Cross-Linked C-telopeptide of type 1 collagen kit (Cloud clone, US). Before starting the assay, the bone was rinsed with phosphate buffered saline (PBS) to remove a blood clot. Then, $20 \mathrm{mg}$ of bone was homogenized with PBS buffer, and centrifuged at $10,000 \times \mathrm{g}$ for 5 minutes. The supernatant was then collected for analysis. The concentration of a CTX-1 level was measured spectrophotometrically at $450 \mathrm{~nm}$ and the assay was conducted according to manufacturer's instruction.

\section{c) Bone estrogen level}

Bone oestrogen level was measured by using Rat Estrogen Elisa kit (Sunlong, China). Bone was rinsed and homogenized with PBS buffer. After centrifugation for 20 minutes at $3000 \mathrm{rpm}$, the supernatant was collected and measured spectrophotometrically at $450 \mathrm{~nm}$. The assay was measured according to manufacturer's instruction.

\section{Data analysis}

The results were analysed using the IBM Statistical Package for Social Sciences software (SPSS) version 23.0 using Analysis of variances (ANOVA) followed by post hoc Tukey's test. Significant value was set at $p<0.05$ and results were presented as mean \pm standard error of the mean (SEM).

\section{RESULTS}

a) Bone Osteocalcin (OC)

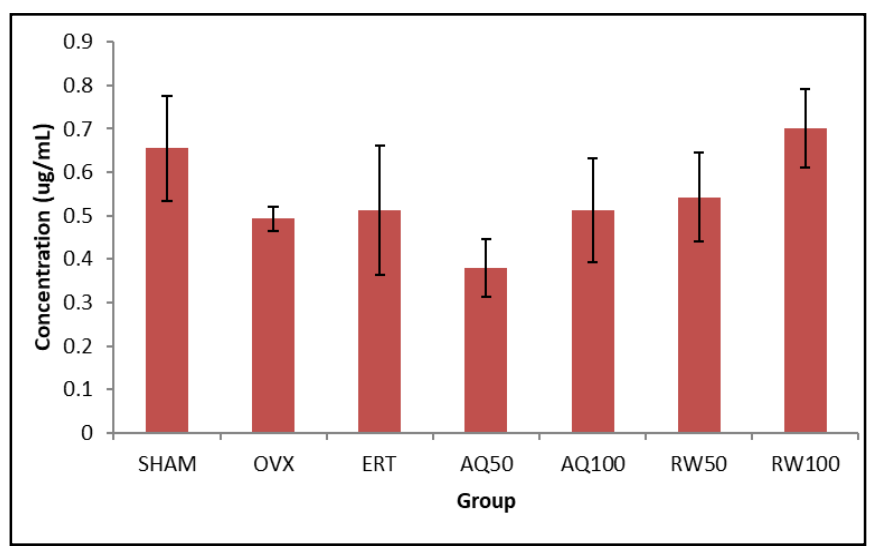

Figure 1. Level of osteocalcin of all groups. Results expressed as mean \pm SEM $(p<0.05)$. found higher in SHAM than OVX group. Ovariectomized rats supplemented with ERT, AQ50, AQ100, RW50 and RW100 showed an increased trend in osteocalcin level albeit not significant.

b) Bone C-Telopeptide of Type 1 Collagen (CTX-1)

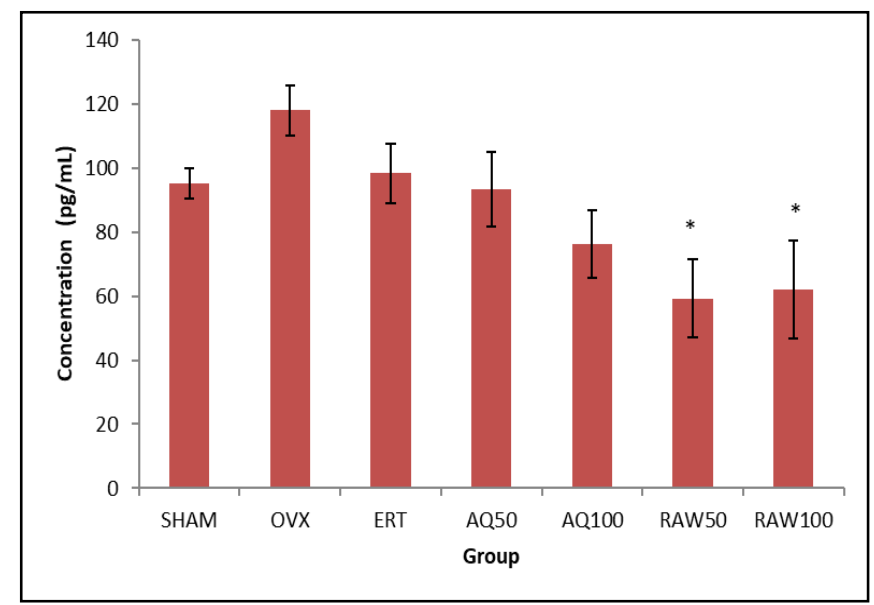

Figure 2 Level of CTX-1 of all groups. Results expressed as mean \pm SEM $(p<0.05)$. '*' indicates significant difference compared to OVX group.

C-telopeptide of type 1 collagen (CTX-1) which is a bone resorption marker was lower in SHAM compared with OVX group. Ovariectomized rats supplemented with ERT, AQ50 and AQ100 showed decreasing trend although not significant. The CTX-1 level of RW50 and RW100 was significantly reduced compared with OVX group.

\section{c) Bone oestrogen level}

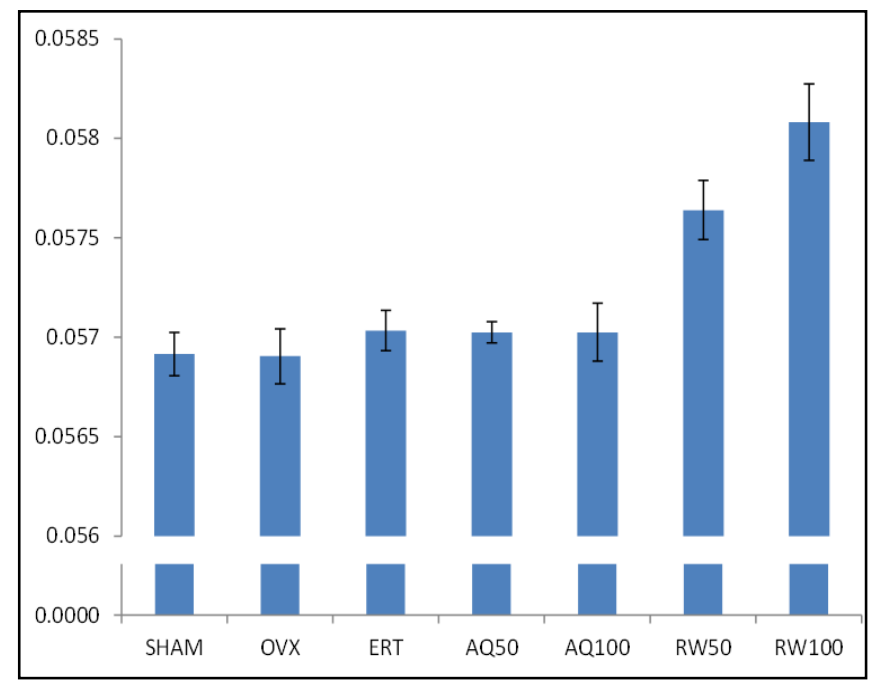

Figure 3 Level of bone oestrogen of all groups. Results expressed as mean \pm SEM $(p<0.05)$. 
The bone oestrogen level was assessed to evaluate FC binding to oestrogen receptor. It was shown that, all treatments: ERT, FC50, FC100, RW50 and RW100 have an increasing trend in oestrogen level compared with OVX group albeit not significant.

\section{DISCUSSION}

Osteoporosis is commonly occurring among women compared to men due to the reduction of oestrogen release following menopause. In this study, the bone metabolism was examined by assessing bone biochemical markers changes which are the osteocalcin (OC) and C-telopeptide of type 1 collagen (CTX-1). Sham-operated (SHAM) group is a control group used to mimic ovariectomy procedure without removal of ovaries to give same stress as other groups to avoid bias. Ovariectomized (OVX) control group as negative control group. In this group, rats were ovariectomized to induce osteoporotic condition ${ }^{31}$ and as an indicator of postmenopausal osteoporosis to be compared with other groups. Estrogen replacement therapy (ERT) group represented as positive control since estrogen is the standard treatment to treat osteoporosis in for postmenopausal women.

Osteocalcin and CTX-1 were chosen as bone markers useful to reflect bone remodelling. ${ }^{32}$ Osteocalcin, a bone formation marker is synthesized by osteoblast. Based on the results, osteocalcin level in OVX group was slightly reduced compared to SHAM group although not significant. However, this result was not in agreement with the previous study as they found osteocalcin level was higher in ovariectomized rats. ${ }^{33}$ They explained that, elevation in osteocalcin level probably due to compensation of bone turnover. Our findings reported that supplementation with AQ100, RW50 and RW100 has potential to increase OC level higher than OVX group. Future studies are warranted to use higher concentrations of Ficus carica (FC) supplementation to improve bone metabolism.

C-telopeptide of type 1 collagen (CTX-1) is a peptide fragment released resulting from osteoclastic resorption process. Garnero et al. ${ }^{34}$ revealed that, post-menopausal women have $86 \%$ higher serum CTX-1 than in premenopausal women and CTX -1 level showed indirectly proportional to bone mineral mass. Based on the results, SHAM group had lower CTX-1 level than OVX group which is consistent with previous literatures. ${ }^{35,36}$ However, a study found that OVX group has high concentration of both markers OC and CTX-1 due to high bone turnover rate. ${ }^{31} \mathrm{Ce}$ et al. ${ }^{37}$ proposed that bone resorbed can be partially balanced with newly formed bone and even the bone resorption rate can outweigh the bone formation rate in osteoporotic condition. Ovariectomized rat introduced with RW 50 and RW100 showed significantly reduced CTX-1 level. These showed that RW50 and RW100 have potential in reducing bone resorption activity thus, preventing bone loss induced by ovariectomy.

Phytoestrogens have been hypothesized to possess a promising alternative treatment for post-menopausal osteoporosis due to its structural similarity to estradiol. Tousen et al. ${ }^{38}$ reported that consumption of low dietary intake of phytoestrogen may reduce bone mineral density (BMD) of post-menopausal women. Hence, phytoestrogen intake may be helpful in preventing bone loss following menopause. Estrogen level was measured to determine the potential oestrogenic activities of FC. In this study, RW50 and RW100 have higher binding affinity to oestrogen receptor compared to ERT, FC50 and FC100 albeit not significant. The result parallels with OC and CTX-1 in which both RW50 and RW100 showed better findings in comparison with FC50 and FC100. Isolation of FC compounds that is responsible to these effects is warranted to explore detailed mechanism in protecting bone loss.

Therefore, based on the results, it was shown that the protective effects of $\mathrm{FC}$ supplementation are due to its anti-resorptive activity even though it has low oestrogenic properties. Currently, Adlina et al. ${ }^{39}$ have reported that, supplementation with raw Ficus carica at $50 \mathrm{mg} / \mathrm{kg}$ and $100 \mathrm{mg} / \mathrm{kg}$ were able to improve bone micro-architecture including significantly reduced trabecular separation, increases trabecular number, significantly increased connectivity density and increases bone volume fraction compared to OVX group. This previous study has supported our result on the protective effects of FC supplementation against bone loss as reflected in bone biochemical markers.

The improvement in bone metabolism of ovariectomized rats supplemented with Ficus carica (FC) may be due to the presence of mineral such as strontium, calcium, magnesium, phosphorus and iron which are essential in developing healthy bones. ${ }^{17}$ In 
addition, FC fruits are rich in bioactive compounds as examples phenolic acid, flavanoid, alkaloid, saponin, anthocyanin and quercetin that contributed to their high antioxidant activities. ${ }^{17,40-42}$ These polyphenols are well known in improving bone health by exhibiting anti-oxidative effects and antiinflammatory actions. ${ }^{19}$ There was a study reported that quercetin inhibited osteoclastogenesis by suppressing the activation of receptor activator of nuclear factor kappa-B ligand (RANKL). ${ }^{43}$

Post-menopausal women are more susceptible to oxidative stress as they have loss the protective effects of oestrogen and may lead to the development of osteoporosis by stimulating osteoclastogenesis via activation of nuclear factor kappa B (NF-kB). ${ }^{44}$ Studies on in vitro antioxidant activities have been investigated by numerous researchers proving that $F C$ possessed high scavenging activities. ${ }^{45,46}$ Therefore, the ability of FC in scavenging free radical may improve bone health by reducing oxidative stress and osteoclast activity. In addition, anti-oxidative effects of FC also have been evaluated in vivo studies showing that FC is able to improve antioxidant defence such as superoxide dismutase, glutathione S-transferase, glutathione reductase and catalase. ${ }^{47}$ Hence, consumption of anti-oxidative compounds from FC may support endogenous antioxidant defence against free radicals and combating reactive oxygen species (ROS) which protect the bone of ovariectomized rats.

Besides, FC also exhibited anti-inflammatory action as it had shown to reduce bone-resorbing cytokines including interleukin (IL) -1 (IL-1), tumor necrosis factor alpha (TNF-a) and IL-6. ${ }^{20}$ The inhibitory effects on these cytokines will suppress bone resorption activity by reducing osteoclast differentiation. ${ }^{25,48}$ Previous study had proven that blockade of either TNF-a or IL-6 will reduce the serum CTX-1. ${ }^{49}$

\section{CONCLUSION}

As a conclusion, in terms of bone biochemical markers and oestrogen level, the effects of FC supplementation were comparative to estrogen replacement therapy. The results showed trends in improving the bone formation marker and oestrogen level. Moreover, a significant reduction has been observed in bone resorption activity of raw Ficus carica at $50 \mathrm{mg} / \mathrm{kg}$ and $100 \mathrm{mg} / \mathrm{kg}$. Therefore, the osteo-protective effects of FC are due to reduction of bone resorption activity rather than bone formation activity. Hence, it may have potential as an anti-osteoporotic agent to replace oestrogen replacement therapy with minimal adverse effect as a treatment for post-menopausal osteoporosis in women. Future studies on the anti-osteoporotic effects of FC with higher doses are warranted to provide a more meaningful mechanistic overview of FC.

\section{CONFLICT OF INTEREST}

The authors declare that they have no competing interests.

\section{ACKNOWLEDGEMENT}

We would like to thank Ministry of higher Education for funding this study (USIM/FRGS/FPSK/32/50216). We also like to thank to Faculty of Medicine and Health Sciences of Universiti Sains Islam Malaysia (USIM) and all the staffs involve in this study.

\section{REFERENCES}

1. Christiansen C. Consensus Development Conference : Prophylaxis and Treatment of Osteoporosis. Am J Med 1993; 94:646-650.

2. Eastell R, O’Neill TW, Hofbauer LC, Langdahl B, Reid IR, Gold DT, et al. Postmenopausal osteoporosis. Nat Rev Dis Prim 2016; 2:16069.

3. Feng X, McDonald JM. Disorders of Bone Remodeling. Annu Rev Pathol Mech Dis 2011; 6:121-145.

4. Khalid AB, Krum SA. Estrogen Receptors Alpha and Beta in Bone. Bone 2016; 87:130-135.

5. Lerner UH. Bone Remodeling in Post-menopausal Osteoporosis. J Dent Res 2006; 85(7): 584-595

6. Chen H, Zhou X, Fujita H, Onozuka M, Kubo K-Y. Age-related changes in trabecular and cortical bone microstructure. Int J Endocrinol 2013; 2013.

7. Khosla S, Burr D, Cauley J, Dempster DW, Ebeling PR, Felsenberg D, et al. Bisphosphonateassociated osteonecrosis of the jaw: report of a task force of the American Society for Bone and Mineral Research. J Bone Miner Res 2007; 22 (10):1479-1491.

8. Body JJ, Bergmann P, Boonen S, Boutsen Y, Devogelaer JP, Goemaere S, et al. Evidence- 
based guidelines for the pharmacological treatment of postmenopausal osteoporosis: A consensus document by the Belgian Bone Club. Osteoporos Int 2010; 21(10):1657-1680.

9. Khosla S, Oursler MJ, Monroe DG. Estrogen and the Skeleton. Trends Endocrinol Metab 2012; 23(11):576-581.

10. Cosman F, de Beur SJ, LeBoff MS, Lewiecki EM, Tanner B, Randall S, et al. Clinician's Guide to Prevention and Treatment of Osteoporosis. Osteoporos Int 2014; 25(10):2359-2381.

11. Hussan F, Ibraheem NG, Kamarudin TA, Shuid AN, Soelaiman IN, Othman F. Curcumin protects against ovariectomy-induced bone changes in rat model. Evidence-based Complement Altern Med 2012; 2012.

12. Seif AA. Nigella Sativa reverses osteoporosis in ovariectomized rats. BMC Complement Altern Med 2014; 14(1): 22.

13. Estai MA, Suhaimi F, Shuid AN, Das S, Abdullah $\mathrm{S}$, Soelaiman I-N. Biomechanical evaluation of fracture healing following administration of Piper sarmentosum in ovariectomised rats. African J Pharm Pharmacol 2012; 6(3):148-156.

14. Fathilah SN, Abdullah S, Mohamed N, Shuid AN. Labisia pumila prevents complications of osteoporosis by increasing bone strength in a rat model of postmenopausal osteoporosis. Evidence-based Complement Altern Med 2012; 2012.

15. Nimse SB, Pal D. Free radicals, natural antioxidants, and their reaction mechanisms. Rsc Adv. Royal Society of Chemistry 2015;5 (35):27986-28006.

16. Al-snafi AE. Nutritional and pharmacological importance of Ficus carica - A review. IOSR J Pharm 2017; 7(3):33-48.

17. Soni N, Mehta S, Satpathy G, Gupta RK. Estimation of nutritional, phytochemical , antioxidant and antibacterial activity of dried fig (Ficus carica). J Pharmacogn Phytochem 2014; 3(2):158-65.

18. Vallejo F, Marín JG, Tomás-Barberán FA. Phenolic compound content of fresh and dried figs ( Ficus carica L.). Food Chem 2012; 130 (3):485-492.

19. Dudarić L, Fužinac-Smojver A, Muhvić D, Giacometti J. The role of polyphenols on bone metabolism in osteoporosis. Food Res Int 2015; 77:290-298.

20. Essa MM, Subash S, Akbar M, Al-Adawi S, Guillemin GJ. Long-Term dietary supplementation of pomegranates, figs and dates alleviate neuroinflammation in a transgenic mouse model of alzheimer's disease. PLoS One 2015; 10(3):1-17.

21. Amessis-Ouchemoukh N, Ouchemoukh $\mathrm{S}$, Meziant N, Idiri Y, Hernanz D, Stinco CM, et al. Bioactive metabolites involved in the antioxidant, anticancer and anticalpain activities of Ficus carica L., Ceratonia siliqua L. and Quercus ilex L. extracts. Ind Crops Prod 2017; 95:6-17.

22. Ahmad S, Bhatti FR, Khaliq FH, Younas T, Madni A, Latif A. In vitro enzymatic investigation of Ficus carica (Fruit). Pak J Pharm Sci 2016; 29 (5):1541-1544.

23. Eteraf-Oskouei $\mathrm{T}$, Allahyari $\mathrm{S}$, AkbarzadehAtashkhosrow A, Delazar A, Pashaii M, Gan SH, et al. Methanolic extract of Ficus carica Linn. leaves exerts antiangiogenesis effects based on the rat air pouch model of inflammation. Evidence-based Complement Altern Med. 2015;2015:1-9.

24. Park S, Han J, Im K, Whang WK, Min H. Antioxidative and anti-inflammatory activities of an ethanol extract from fig (Ficus carica) branches. Food Sci Biotechnol 2013; 22(4):1071 1075.

25. Yokota K, Sato K, Miyazaki T, Kitaura H, Kayama $\mathrm{H}$, Miyoshi $\mathrm{F}$, et al. Combination of tumor necrosis factor $a$ and interleukin -6 induces mouse osteoclast-like cells with bone resorption activity both in vitro and in vivo. Arthritis Rheumatol 2014; 66(1):121-129.

26. Wei S, Kitaura H, Zhou P, Ross FP, Teitelbaum SL. IL-1 mediates TNF-induced osteoclastogenesis. J Clin Invest 2005; 115 (2):282-290.

27. Wheater G, Elshahaly M, Tuck SP, Datta HK, van Laar JM. The clinical utility of bone marker measurements in osteoporosis. J Transl Med 2013; $11(1): 201$.

28. Al-Anazi AF, Qureshi VF, Javaid K, Qureshi S. Preventive effects of phytoestrogens against postmenopausal osteoporosis as compared to the available therapeutic choices: An overview. J Nat Sci Biol Med 2011;2(2):154-163.

29. Fathilah SN, Mohamed N, Muhammad N, Mohamed IN, Soelaiman IN, Shuid AN. Labisia pumila regulates bone-related genes expressions in postmenopausal osteoporosis model. BMC Complement Altern Med 2013; 13 (217):1-7. 
30. Sophocleous A, Idris Al. Rodent models of osteoporosis. Bonekey Rep 2014; (614).

31. Yoon KH, Cho DC, Yu SH, Kim KT, Jeon Y, Sung JK. The change of bone metabolism in ovariectomized rats: Analyses of MicroCT scan and biochemical markers of bone turnover. J Korean Neurosurg Soc 2012; 51(6):323-327.

32. Jovčevska J, Stratrova S, Gjorgovski I, Gruev $\mathrm{T}$, Kotevska M, Janićević-Ivanovska $\mathrm{D}$, et al. Bone Turnover Markers Relations to Postmenopausal Osteoporosis. J Med Biochem 2009; 28(3):161-165.

33. Elkomy MM, Elsaid FG. Anti-osteoporotic effect of medical herbs and calcium supplementation on ovariectomized rats. J Basic Appl Zool 2015; 72:81-88.

34. Garnero P, Borel O, Delmas PD. Evaluation of a fully automated serum assay for C-terminal cross-linking telopeptide of type I collagen in osteoporosis. Clin Chem 2001; 47(4):694-702.

35. Aktifanus AT, Shuid ANA, Rashid NHA, Ling TH, Loong CY, Saat NM, Muhammad N, et al. Comparison of the Effects of Tocotrienol and Estrogen on the Bone Markers and Dynamic Changes in Postmenopausal Osteoporosis Rat Model. Asian J Anim Vet Adv 2012; 7(3):225234.

36. Zhang DW, Deng H, Qi W, Zhao GY, Cao XR. Osteoprotective effect of cordycepin on estrogen deficiency-induced osteoporosis in vitro and in vivo. Biomed Res Int 2015;2015.

37. Ce C, Zhou L, Yu D, Zhao Y, Yang N. Serum osteocalcin levels and bone mineral density in ovariectomized rats. Int J Innov Sci Res 2014; 5(1):1-8.

38. Tousen $Y$, Ezaki J, Fujii Y, Ueno T, Nishimuta M, Ishimi Y. Natural S-equol decreases bone resorption in postmenopausal, non-equolproducing Japanese women: A pilot randomized, placebo-controlled trial. Menopause 2011; 18(5):563-274.

39. Mohammad A, Razaly NI, Dzulkhairi M, Rani M, Shamsir M, Aris M, et al. A Micro-Computed Tomography (micro-CT) Analysis of Postmenopausal Osteoporotic Rat Models Supplemented with Ficus carica. J Appl Pharm Sci 2018;8(6):39-45.

40. Slatnar A, Klancar U, Stampar F, Veberic R. Effect of drying of figs (Ficus carica L.) on the contents of sugars, organic acids, and phenolic compounds. J Agric Food Chem 2011; 59(21):11696-11702.
41. Solomon A, Golubowicz S, Yablowicz Z eev, Grossman S, Bergman M, Gottlieb HE, et al. Antioxidant Activities and Anthocyanin Content of Fresh Fruits of Common Fig (Ficus carica L .). J Agric Food Chem 2006; 54(20):77177723.

42. Wojdyło A, Nowicka P, Carbonell-Barrachina ÁA, Hernández F. Phenolic compounds, antioxidant and antidiabetic activity of different cultivars of Ficus carica L. fruits. J Funct Foods 2016; 25:421-432.

43. Pang JL, Ricupero DA, Huang S, Fatma N, Singh DP, Romero JR, et al. Differential activity of kaempferol and quercetin in attenuating tumor necrosis factor receptor family signaling in bone cells. Biochem Pharmacol 2006; 71 (6):818-826.

44. Xing L, Bushnell TP, Carlson L, Tai Z, Tondravi $M$, Siebenlist $U$, et al. NF- B p50 and p52 Expression Is Not Required for? RANKExpressing Osteoclast Progenitor Formation but Is Essential for RANK- and CytokineMediated Osteoclastogenesis. J bone Miner Res 2002; 17(7):1200-1210.

45. Ammar S, Contreras M del M, Belguith-Hadrich O, Segura-Carretero A, Bouaziz M. Assessment of the distribution of phenolic compounds and contribution to the antioxidant activity in Tunisian fig leaves, fruits, skins and pulps using mass spectrometry-based analysis. Food Funct 2015; 6(12):3663-3677.

46. Loizzo MR, Bonesi M, Pugliese A, Menichini F, Tundis R. Chemical composition and bioactivity of dried fruits and honey of Ficus carica cultivars Dottato, San Francesco and Citrullara. J Sci Food Agric 2014; 94(11):21792186.

47. Subash S, Essa MM, Al-asmi A, Al-adawi S, Vaishnav R. Chronic Dietary Supplementation of $4 \%$ Figs on the Modification of Oxidative Stress in Alzheimer' s Disease Transgenic Mouse Model. Biomed Res Int 2014;2014.

48. Weitzmann MN, Pacifici R. Estrogen deficiency and bone loss: An inflammatory tale. J Clin Invest 2006; 116(5):1186-1194.

49. Charatcharoenwitthaya N, Khosla S, Atkinson EJ, McCready LK, Riggs BL. Effect of Blockade of TNF- $\alpha$ and Interleukin-1 Action on Bone Resorption in Early Postmenopausal Women. J Bone Miner Res 2007; 22(5):724-729. 